\title{
Curcumin enhances the response of non-Hodgkin's lymphoma cells to ionizing radiation through further induction of cell cycle arrest at the G2/M phase and inhibition of mTOR phosphorylation
}

\author{
QIAO QIAO $^{1}$, YUANJUN JIANG ${ }^{2}$ and GUANG LI ${ }^{1}$
}

Departments of ${ }^{1}$ Radiotherapy and ${ }^{2}$ Urology, The First Hospital of China Medical University, Shenyang 110001, P.R. China

Received August 20, 2012; Accepted September 27, 2012

DOI: $10.3892 / o r .2012 .2091$

\begin{abstract}
It is crucial to enhance tumor radiosensitivity for the purpose of both lowering the dose of ionizing radiation (IR) and achieving higher antitumor efficacy. We identified curcumin as a radiosensitizer to enhance non-Hodgkin's lymphoma (NHL) cell response to IR in vitro and further investigated the mechanism mediating this effect. We treated Namalwa, Ramos and Raji cell lines with vehicle, curcumin, IR and curcumin-IR. Cell viability and cell cycle distribution were determined to ascertain the radiosensitization effect of curcumin. DNA damage-related proteins, cell cycle regulatory proteins, phosphorylation of mammalian target of rapamycin (mTOR) and the nuclear translocation of the downstream nuclear factor- $\kappa \mathrm{B}(\mathrm{NF}-\kappa \mathrm{B})$ target were examined by western blotting. Treatment with curcumin led to decreased viability of all three types of NHL cells and had a profound radiosensitization effect. Pre-treatment with curcumin at a low concentration of $2 \mu \mathrm{mol} / 1$ increased IR-induced G2/M arrest in the cell cycle and increased the expression of cyclin-dependent kinase inhibitors, p21 cip1 and p53. However, this effect was blocked when NHL cells were pre-treated with $10 \mu \mathrm{mol} / \mathrm{l}$ of KU55933, a specific inhibitor of ataxia-telangiectasia-mutated (ATM). Pre-treatment with curcumin inhibited the phosphorylation of mTOR and the nuclear translocation of the downstream $\mathrm{NF}-\kappa \mathrm{B}$ target induced by IR. Curcumin enhanced the cell response to IR in NHL mediated through the induction of G2/M phase arrest and the inhibition of both a constitutive and IR-induced activation of the mTOR-NF- $\kappa$ B pathway. This offers great potential for curcumin to be used in conjunction with radiotherapy for NHL in order to increase the efficiency of the treatment.
\end{abstract}

Correspondence to: Dr Guang Li, Department of Radiotherapy, The First Hospital of China Medical University, Shenyang 110001, P.R. China

E-mail: jiangqiao521@hotmail.com

Key words: lymphoma, curcumin, radiation, cell cycle arrest, ataxia-telangiectasia-mutated, mammalian target of rapamycin

\section{Introduction}

Non-Hodgkin's lymphoma (NHL) represents heterogeneous lymphoproliferative malignancies with differing patterns of behavior and therapy response (1). Traditionally, ionizing radiation (IR) therapy plays an important role in the management of NHL. IR alone is an effective therapy for stages I and II in indolent NHL patients. While indolent and aggressive NHLs are responsive to IR and chemotherapy, approximately $50-70 \%$ of the patients relapse (2). It is suggested that a poor prognosis of NHL may be due to its resistance to cell death induction by IR or chemotherapy. Therefore, future improvements in the therapeutic index for radiotherapy are required to target resistant cells and improve efficacy without toxicity.

Curcumin (diferuloylmethane), a major constituent of turmeric powder, is extracted from the rhizomes of the plant Curcuma longa. Numerous studies have demonstrated the effectiveness of curcumin as an anticancer drug or chemopreventive agent in laboratory animal models of human carcinogenesis including NHL (3-6) without cytotoxic effects on healthy cells (7). Inhibition of cell growth and induction of apoptosis is the common mechanism by which curcumin demonstrates its anticancer effects. In addition to the effectiveness of curcumin alone, it is being currently evaluated in combination therapy with IR or chemotherapy. Curcumin has exhibited varying effects on radiation sensitivity in different cancer cell types and its effect as a radiosensitizer has been supported in a variety of tumors including prostate, colorectal and ovarian cancers (8-12). Likewise, we previously demonstrated that curcumin may enhance IR-induced apoptosis in NHL (13).

Accumulating evidence suggests that multiple signaling pathways, including inhibition of nuclear factor- $\kappa \mathrm{B}(\mathrm{NF}-\kappa \mathrm{B})$, are involved in mediating the effect of curcumin on the growth suppression of human cancer cells $(4,14-18)$. The mammalian target of rapamycin (mTOR), an atypical serine/threonine $(\mathrm{S} / \mathrm{T})$ protein kinase, plays a central role in controlling cell growth, proliferation and metabolism $(19,20)$. Activation of the mTOR pathway was noted in melanoma (21), squamous cell cancers (22), adenocarcinomas (23), colorectal cancers (24) and lymphomas (25). Increasing lines of evidence suggest that curcumin may exert its antiproliferative effects 
by inhibiting mTOR signaling directly or indirectly and thus may represent a new class of mTOR inhibitors (26).

The ability of curcumin to alter the redox status of transformed cells (27) and its desirable safety profile prompted us to investigate whether it may also alter radiation sensitivity in NHL. In this study, we investigated the mechanism of action for curcumin's effect on IR cytotoxic activity in NHL cells. Since NHL is often resistant to IR-induced cell death induction, we specifically examined how curcumin induces cell death. Therefore, we searched for molecular mechanisms that were associated with susceptibility to cell death. We were able to highlight a novel mechanism by which curcumin caused G2/M cell cycle arrest in NHL cells at concentrations that were very close to its plasma-achievable concentrations in humans. In this study, curcumin was identified as a radiosensitizer in NHL cells. Furthermore, its effects were mediated through the inhibition of IR-induced mTOR-NF- $\kappa \mathrm{B}$ activation.

\section{Materials and methods}

Reagents. Ataxia-telangiectasia-mutated (ATM)-kinase inhibitor, KU55933, was purchased from Calbiochem (an affiliate of Merck KGaA). Curcumin, RNase A, propidium iodide and rapamycin (mTOR inhibitor) were purchased from SigmaAldrich (St. Louis, MO, USA). Antibodies against p53 (sc-6243) and $\beta$-actin (C4, sc-47778) were purchased from Santa Cruz Biotechnology, Inc. (Santa Cruz, CA, USA). Antibodies against phosphorylated and nonphosphorylated mTOR (Ser2448), p65, p21Waf1, p53, phospho-ATM (Ser-1981), ATM and DNA polymerase $\beta-1$ were purchased from Cell Signaling Technology, Inc. (Danvers, MA, USA). Electrophoresis reagents, cDNA synthesis kits, SYBR-Green Master Mix and iQ5 software were all obtained from Bio-Rad (Hercules, CA, USA). Unless otherwise indicated, all other chemicals used in this study were purchased from Sigma-Aldrich.

Cell lines and culture. Three human lymphoma cell lines (Namalwa, Ramos and Raji) were purchased from the American Type Culture Collection. The cells were maintained in Roswell Park Memorial Institute (RPMI)-1640 medium (Sigma-Aldrich) supplemented with $10 \%$ fetal calf serum (Invitrogen Life Technologies, Carlsbad, CA, USA), 100 U/ml penicillin and $100 \mathrm{mg} / \mathrm{ml}$ streptomycin in a humidified incubator at $37^{\circ} \mathrm{C}$ in the presence of $95 \%$ air and $5 \% \mathrm{CO}_{2}$.

Cell treatment. Curcumin (98\% purity) was dissolved in dimethyl sulfoxide (DMSO, final concentration $0.5 \%$ ) to produce a $100 \mathrm{mmol} / \mathrm{l}$ stock solution. IR was delivered in a Siemens Primus accelerator (Hamburg, Germany) at $6 \mathrm{MV}$ at room temperature (dose rate: $200 \mathrm{cGy} / \mathrm{min}$ ). Control cells were not irradiated but they were removed from the incubator and were then placed at the radiation site for the same period of radiation as the irradiated cells. For combined treatment with curcumin, rapamycin or KU55933 and IR treatment, cells were kept at $37^{\circ} \mathrm{C}$ with the indicated agent for $4 \mathrm{~h}$ prior to IR treatment.

Cell viability assay. Cell viability was determined with the tetrazolium salt water-soluble tetrazolium salt assay (Roche Diagnostics GmbH, Penzberg, Germany) as previously described (13). The results were expressed as a percentage of cell viability for each concentration of curcumin with respect to the controls.

Cell cycle analysis. The cell cycle distribution was determined by staining with propidium iodide (PI) as previously described (28). After treatment with curcumin (2 and $10 \mu \mathrm{mol} / \mathrm{l})$, $1 \times 10^{6}$ cells were harvested and fixed in $70 \%$ ethanol at $4^{\circ} \mathrm{C}$ overnight. The cells were washed twice in ice-cold PBS, were treated with RNase for $1 \mathrm{~h}$ and their DNA was stained with PI solution $(50 \mathrm{mg} / \mathrm{ml})$ for $30 \mathrm{~min}$ in the dark. The cell cycle distribution was determined using FACSAria II flow cytometer (Becton Dickinson, San Diego, CA, USA) using Cell Quest software.

Subcellular fractionation. Namalwa, Ramos and Raji cells were incubated with various stimuli for the indicated times, and the total and nuclear extracts were obtained as previously described (13). The protein content was measured by the Bradford method (Bio-Rad, Hercules, CA, USA). Following analysis of protein content, $20 \mu \mathrm{g}$ of both fractions was subjected to SDS-polyacrylamide gel electrophoresis and examined by western blotting.

Western blot analysis. Equal amounts of lysate protein $(20 \mu \mathrm{g})$ were separated by SDS-polyacrylamide gel electrophoresis, transferred to polyvinylidene difluoride membranes and blocked in 5\% non-fat milk in PBS for $1 \mathrm{~h}$. The membranes were probed with the primary antibodies mentioned above in the Reagents section. Membranes were re-probed with anti- $\beta$ actin antibody at the concentration of 1:5,000. The antibodies were detected using a chemiluminescence detection kit (LumiGLO; Cell Signaling Technology, Inc.) according to the manufacturer's instructions.

Statistical analysis. Data are presented as the means \pm SEM. Comparison between groups was performed with the paired Student's t-test and the level of statistical significance was determined to be $\mathrm{P}<0.05$.

\section{Results}

Effects of curcumin on cell viability in human lymphoma cell lines. We assessed the antiproliferative effect of curcumin on NHL cell lines. Namalwa, Ramos and Raji cells were treated with 2,10 and $20 \mu \mathrm{mol} / 1$ of curcumin for $48 \mathrm{~h}$. The viability of the three lymphoma cell lines was decreased by curcumin treatment in a dose-dependent manner (Fig. 1A). However, a lower concentration $(2 \mu \mathrm{mol} / \mathrm{l})$ of curcumin did not display an impact on the viability of NHL cells $(\mathrm{P}>0.05)$.

To examine whether this antiproliferative effect was permanent or transient, we further assessed the capacity of the cultures to recover from curcumin treatment. After incubation with curcumin for $48 \mathrm{~h}$, cells were further incubated for $48 \mathrm{~h}$ in the absence of curcumin. Treatment with 10 and $20 \mu \mathrm{mol} / 1$ curcumin markedly inhibited the recovery of all cell lines, indicating substantial injury to DNA repair and replication (Fig. 1B).

Curcumin enhances the antiproliferative effect of ionizing radiation. To examine the radiosensitization effect of 


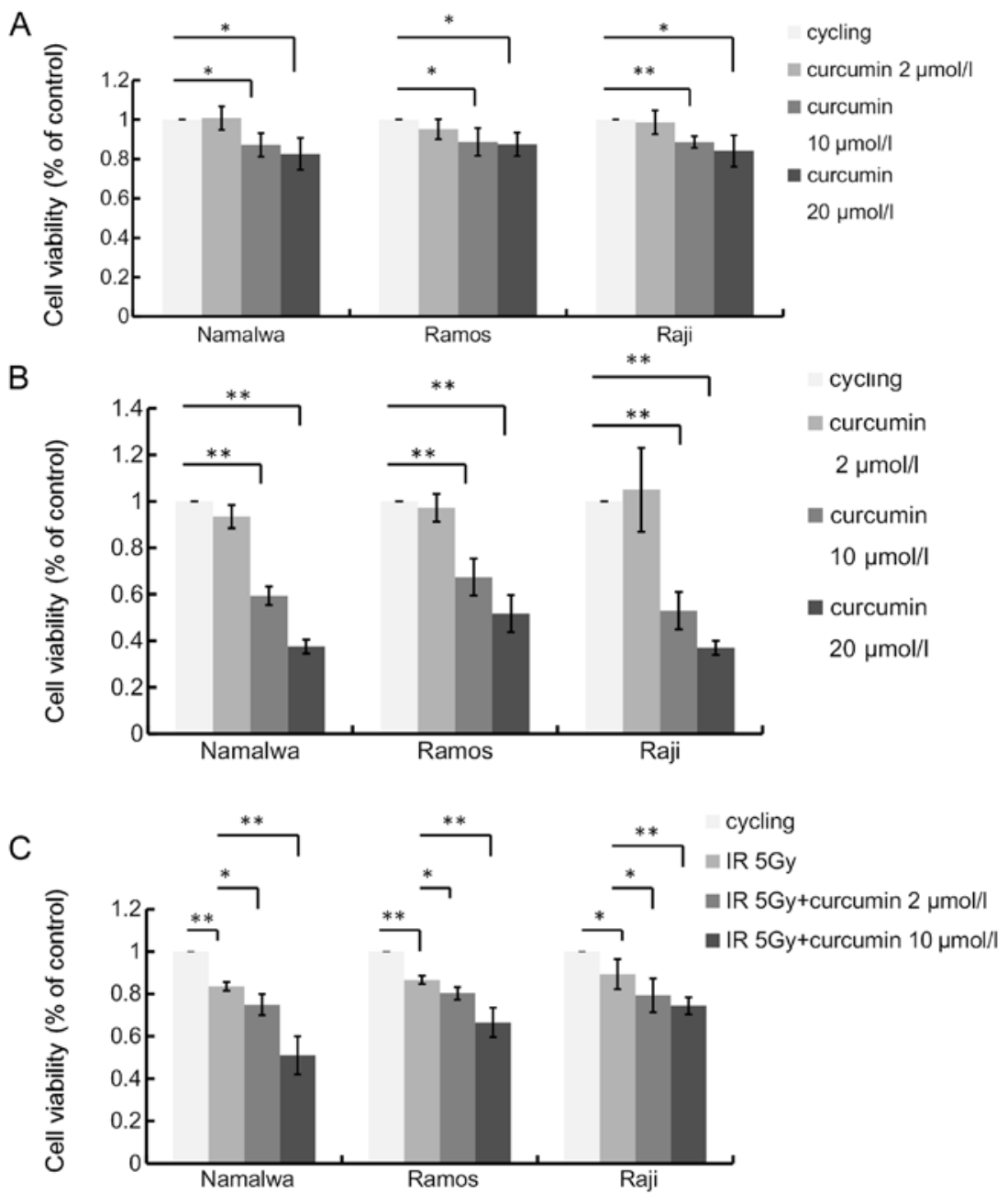

Figure 1. Curcumin enhances the antiproliferative effect of ionizing radiation (IR) in human NHL cell lines. (A) After treatment with 2,10 and $20 \mu$ mol/1 of curcumin for $48 \mathrm{~h}$, cell viability was determined. Data are presented as the means $\pm \mathrm{SE}\left({ }^{*} \mathrm{P}<0.05,{ }^{* * *} \mathrm{P}<0.01\right.$ compared with the untreated cells in paired Student's t-test). (B) Curcumin was removed after $48 \mathrm{~h}$ of treatment. Cells were allowed to recover for another $48 \mathrm{~h}$ and the viability assay was repeated. Data are presented as the means $\pm \mathrm{SE}\left({ }^{*} \mathrm{P}<0.05,{ }^{* *} \mathrm{P}<0.01\right.$ compared with the untreated cells in paired Student's t-test). (C) NHL cells were treated with IR (5 Gy) or a combination of curcumin ( 2 or $10 \mu \mathrm{mol} / 1,4 \mathrm{~h}$ before IR) and IR (5 Gy). Cell viability was evaluated $48 \mathrm{~h}$ after the treatment. Data are presented as the means $\pm \mathrm{SE}\left({ }^{*} \mathrm{P}<0.05,{ }^{* *} \mathrm{P}<0.01\right.$ compared with untreated cells or cells treated with IR alone in paired Student's t-test).

curcumin on human lymphoma cells, we further investigated the effects of curcumin pre-treatment on radiation-induced cell death (Fig. 1C). The treatment with 5 Gy IR resulted in growth inhibition. The percentage of cells that survived at $48 \mathrm{~h}$ were $83.51 \pm 2.27,86.68 \pm 2.13$ and $89.30 \pm 7.21 \%$ in Namalwa, Ramos and Raji cells, respectively. Curcumin significantly augmented the IR-induced inhibition of survival in the three cell lines. Although the low dose $(2 \mu \mathrm{mol} / \mathrm{l})$ of curcumin displayed no cytotoxicity on NHL cells, it enhanced the IR-induced cell death. Compared with IR alone, the combined treatment led to even less cell survival down to $74.90 \pm 5.52,80.39 \pm 3.28$ and $79.30 \pm 7.43 \%$ in the three NHL cell lines, respectively $(\mathrm{P}<0.05)$. In order to better demonstrate the potential clinical benefit of curcumin in combination with radiotherapy, we selected a curcumin dose of 2 and $10 \mu \mathrm{mol} / 1$ for $4 \mathrm{~h}$ as the pre-treatment condition used in further molecular studies. Taken together, these results clearly demonstrated that curcumin treatment sensitized these tumor cell lines to IR.

Curcumin induces IR-mediated DNA damage. DNA polymerase $\beta$ is crucial in the repair of DNA strand breaks (29). To investigate whether the DNA-damaging effect is involved in the sensitization of the IR-induced antiproliferative effect by curcumin, we analyzed the expression of molecules involved in the regulation of DNA damage repair by western blot analysis. Our results demonstrated that curcumin treatment decreased the expression of DNA polymerase $\beta$ and enhanced the IR-induced inhibition of DNA polymerase $\beta$ (Fig. 2A).

Considering that phosphorylation of ATM is an indicator of the presence of DNA double-strand breaks (30), we further analyzed the phosphorylation of ATM at Ser-1981. We observed an increased expression of phosphorylated ATM by IR or curcumin in either of the doses without any changes in the total ATM protein level (Fig. 2B). This effect was more prominent when NHL cells were treated with a combination of curcumin and IR.

Curcumin enhances IR-induced G2/M arrest in lymphoma cells. To gain further insight into curcumin's mechanism of action for the cell sensitization to IR-induced growth inhibition, we analyzed the distribution of the cell cycle by flow cytometry. Both curcumin $(10 \mu \mathrm{mol} / \mathrm{l})$ and IR treatment caused G2/M 

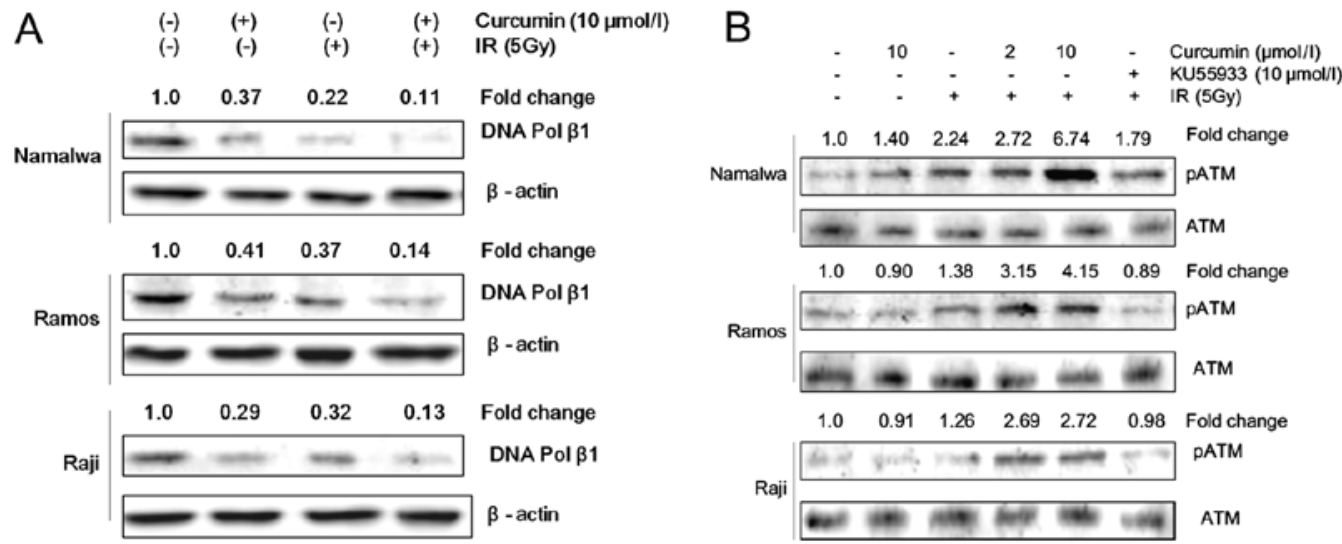

Figure 2. Curcumin treatment attenuated the DNA damage induced by ionizing radiation (IR) in NHL cells. Each NHL cell line was pretreated with 2 or $10 \mu \mathrm{mol} / 1$ curcumin for $4 \mathrm{~h}$ followed by radiation treatment $(5 \mathrm{~Gy}$ ). Twenty-four hours after irradiation, total lysate was prepared as described in the Materials and methods section. Representative western blotting demonstrated the effect of curcumin treatment in NHL cells on the expression or phosphorylation of (A) DNA polymerase $\beta$ as well as (B) p-ATM (Ser-1981) and ATM. Each blot was stripped and reprobed with anti- $\beta$-actin antibody to ensure equal protein loading. Intensities of immunoreactive bands were quantified by densitometric scanning.
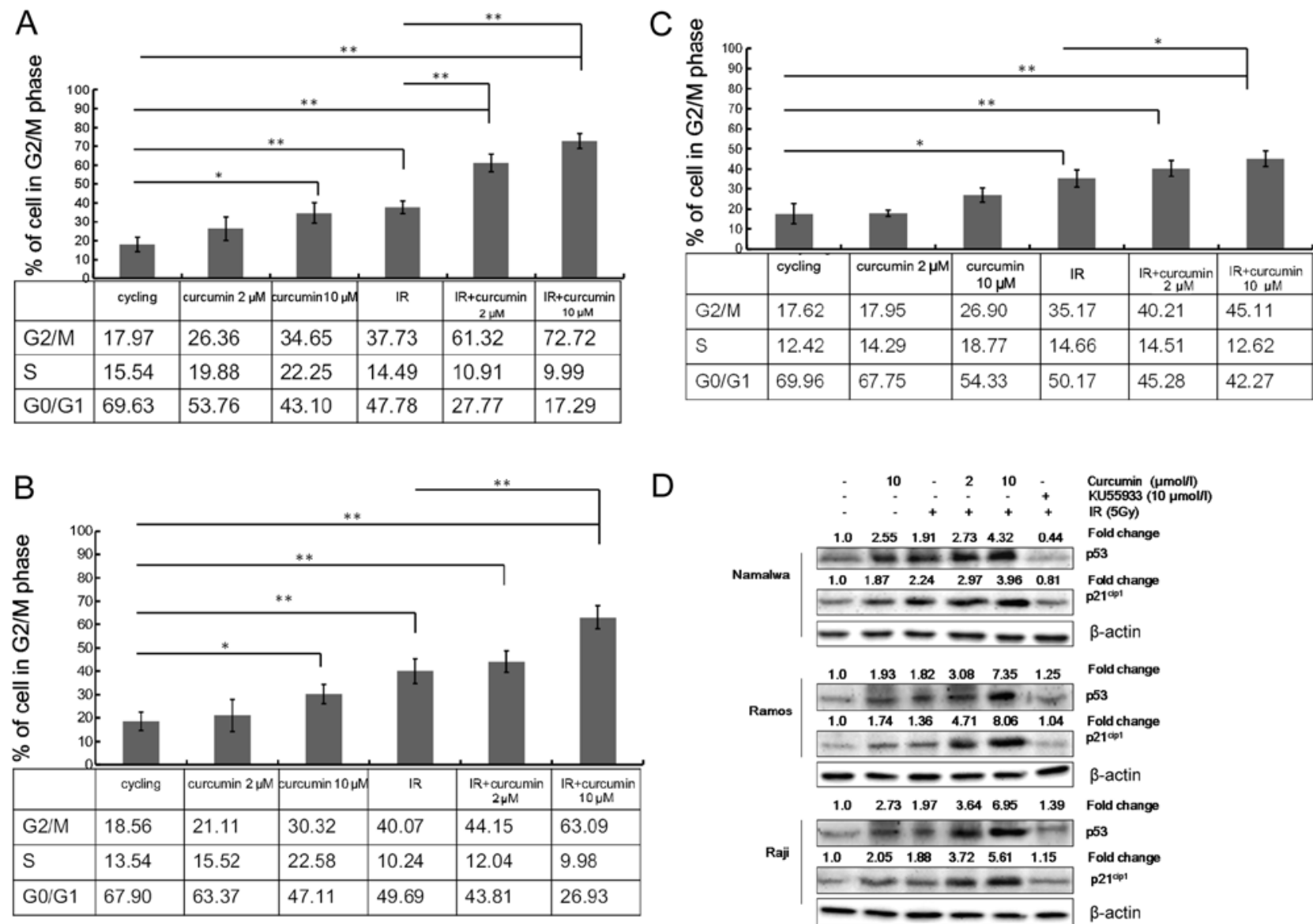

Figure 3. Curcumin enhances ionizing radiation (IR)-induced G2/M phase arrest in NHL cells. (A) Namalwa, (B) Ramos and (C) Raji cells were treated with 2 or $10 \mu \mathrm{mol} / 1$ curcumin for $4 \mathrm{~h}$ and were further exposed to an X-ray radiation of $5 \mathrm{~Gy}$. The cell cycle distribution was determined by FACS analysis $24 \mathrm{~h}$ after IR as described in Materials and methods. Each column represents the average and standard error of 3 independent experiments. Data are presented as the means $\pm \mathrm{SE}\left({ }^{*} \mathrm{P}<0.05,{ }^{* *} \mathrm{P}<0.01\right.$ compared with untreated cells in paired Student's t-test). (D) Curcumin induces cell cycle redistribution through increasing IR-induced upregulation of p53 and p21 expression. Cells were treated with DMSO, 2 or $10 \mu \mathrm{mol} / 1$ curcumin, IR (5 Gy) or were pretreated with 2 or $10 \mu \mathrm{mol} / 1$ of curcumin for $4 \mathrm{~h}$ followed by $5 \mathrm{~Gy}$ of IR and were harvested $24 \mathrm{~h}$ later. Whole-cell lysates were analyzed by western blot analysis as described in Materials and methods ( $\beta$-actin served as a loading control).

cell cycle arrest and this effect was more prominent with the combined treatment of curcumin and IR. A low concentration of curcumin $(2 \mu \mathrm{mol} / \mathrm{l})$ increased the percentage of lymphoma cells that arrested in the G2/M phase due to the effect of IR. However, this low dose alone (without IR) had little effect on G2/M phase arrest. Exposure of 5 Gy of IR induced G2/M 

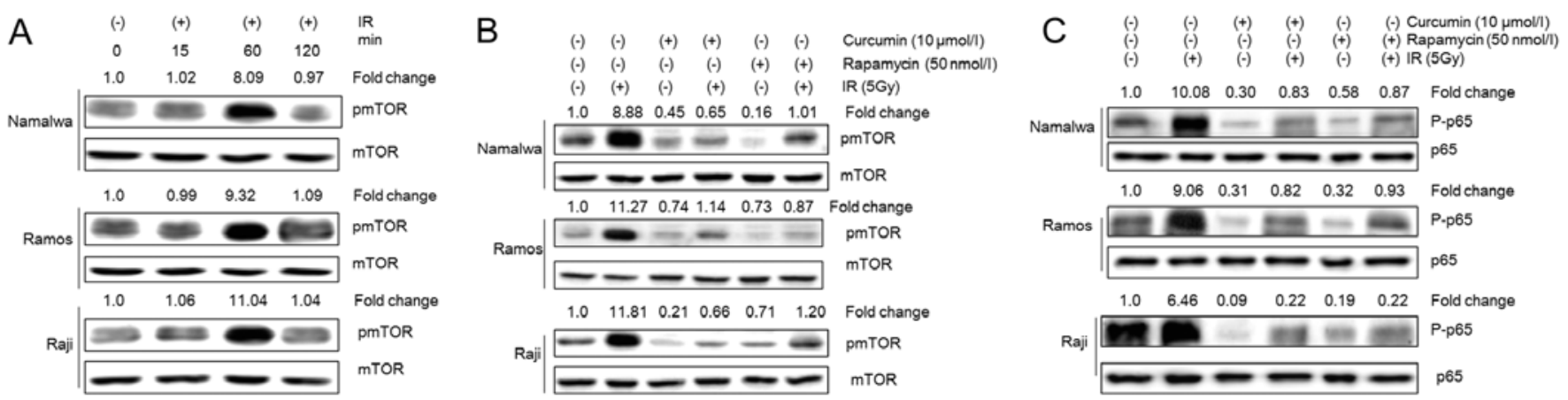

Figure 4. Curcumin inhibits constitutive and ionizing radiation (IR)-induced mTOR and p65 phosphorylation. (A) NHL cells were treated with IR (0 or 5 Gy) and lysed at the indicated time points after IR exposure. The cells were subjected to western blot analysis. (B) NHL cells were treated with $10 \mu$ mol/l of curcumin, $50 \mathrm{nmol} / 1$ of rapamycin or the vehicle for $4 \mathrm{~h}$, followed by treatment with or without IR (5 Gy). The cells were lysed $1 \mathrm{~h}$ after IR exposure and were subjected to western blot analysis using the indicated antibodies (pmTOR was normalized to total mTOR levels). (C) NHL cells were treated as described in B (P-p65 was normalized to total p65 levels).

phase arrest in $37.73 \pm 3.31,40.07 \pm 3.32$ and $35.17 \pm 4.38 \%$ of Namalwa, Ramos and Raji cells, respectively. However, the pre-treatment of cells with $2 \mu \mathrm{mol} / 1$ of curcumin followed by IR led to a significant increase in $\mathrm{G} 2 / \mathrm{M}$ phase arrest in Namalwa, Ramos and Raji cells $(61.32 \pm 4.59,44.15 \pm 4.65$ and $40.21 \pm 3.97 \%$, respectively). Meanwhile, the proportion of cells in the $\mathrm{G} 0 / \mathrm{G} 1$ phase was concomitantly decreased following the combined treatment of IR and curcumin ( $2 \mu \mathrm{mol} / \mathrm{l})$ (Fig. 3A-C).

Curcumin enhances the IR induction of cell cycle regulatory proteins. DNA damage generally leads to the activation of the ATM pathway $(31,32)$. To further delineate the molecular mechanism of curcumin on enhanced IR-induced G2/M arrest, western blot analysis was used to determine the effect of curcumin on selected proteins that are involved in cell cycle regulation. Treatment of the cells with $10 \mu \mathrm{mol} / \mathrm{l}$ curcumin or IR displayed an increase in the expression of cyclin-dependent kinase inhibitors $\mathrm{p} 21^{\text {cip1 }}$ and $\mathrm{p} 53$ as compared to the DMSOtreated control cells (Fig. 3D). The treatment with combined curcumin and IR further increased the expression of both the p53 and p21 ${ }^{\text {cip } 1}$ proteins as compared to the treatment with either of them alone.

We aimed to explore whether enhanced phosphorylation of ATM plays a role in the effect of curcumin on IR-induced cell cycle redistribution. NHL cells were incubated with an ATM-specific inhibitor, KU55933, (33) and were further subjected to curcumin treatment for $4 \mathrm{~h}$ followed by IR exposure. Pre-incubation with $10 \mu \mathrm{mol} / 1$ KU55933 prevented IR-induced ATM phosphorylation but also suppressed curcumin-enhanced activation of $\mathrm{p} 53$ and $\mathrm{p} 21^{\text {cipl }}$ by IR (Fig. 3D). Previous studies have demonstrated that pre-treatment of cells with $20 \mu \mathrm{mol} / 1$ of curcumin for $4 \mathrm{~h}$ significantly suppressed the IR-induced overexpression of $\mathrm{CDC} 2$ and cyclin $\mathrm{B} 1$ in all three cell lines (13) These results provide further evidence for the possible involvement of ATM/p53/p2 $1^{\text {cipl }}$ in the G2/M cell cycle arrest caused by curcumin.

Curcumin inhibits the IR-induced mTOR-NF- $\kappa B$ pathway activation. To investigate the effect of curcumin on mTOR activity in lymphoma cells, the regulation of mTOR phosphorylation by curcumin was examined. The treatment with $10 \mu \mathrm{mol} / \mathrm{l}$ of curcumin led to decreased phosphorylation of mTOR. Likewise, IR exposure induced mTOR phosphorylation in NHL cells, which reached the maximal level approximately $1 \mathrm{~h}$ after the irradiation (Fig. 4A). However, pre-treatment with curcumin $(10 \mu \mathrm{mol} / \mathrm{l})$ inhibited the mTOR phosphorylation that was induced by IR (Fig. 4B).

A 4-h treatment of NHL cells with rapamycin, a specific inhibitor of mTOR, markedly inhibited mTOR phosphorylation in NHL cells. However, when NHL cells were pretreated with rapamycin followed by IR, the IR-induced mTOR phosphorylation was suppressed (Fig. 4B).

We previously demonstrated that IR induced p65 phosphorylation in NHL cells $4 \mathrm{~h}$ after IR (13) and curcumin pre-treatment inhibited its nuclear translocation. However, the mechanism through which curcumin regulates the activation of NF- $\mathrm{KB}$ is not clear. Previous studies have demonstrated that mTOR inhibition led to a reduced expression of P65 in various cancer cell types (34). In this study, it was demonstrated that the treatment of NHL cells with rapamycin inhibited constitutively the expression of p65 and suppressed the IR-induced p65 phosphorylation. This may be indicative of the possibility that mTOR regulates the activation of NF- $\mathrm{KB}$ in NHL cells (Fig. 4C). Taken together, the results of this study suggest that the regulation of NF- $\mathrm{KB}$ by curcumin in combination with IR is mediated by mTOR.

\section{Discussion}

In the present study, it was demonstrated that curcumin exerted cytotoxicity on NHL cells at high concentrations. Furthermore, pre-treatment of these cells with curcumin enhanced the cell response to ionizing radiation (IR) even at lower concentrations of curcumin, where curcumin alone failed to display any direct cytotoxicity in lymphoma cells. We also investigated the mechanism of action for the cell cycle arrest involved in the effect of curcumin treatment that is mediated through the DNA damage pathway. Curcumin was able to increase the G2/M cell cycle arrest induced by IR. This effect was probably mediated though the activation of the cell cycle regulators p53 and p21 that was in turn dependent on the increased ATM phosphorylation indicating the presence of DNA double-strand 
breaks. IR induced mTOR phosphorylation in NHL cells within $1 \mathrm{~h}$ after IR exposure and pre-treatment with curcumin (10 $\mu \mathrm{mol} / \mathrm{l})$ inhibited this effect.

It has been well documented that curcumin possesses antitumor activity through the inhibition of proliferation, invasion, angiogenesis and induction of apoptosis and cell cycle redistribution (35). However, susceptibility to curcumin varies among different cell lines, indicating that it has either multiple targets that are expressed in a cell-specific manner or one target that affects cell-specific pathways. We reported that the cytotoxic effects of curcumin and IR in NHL may be mediated through the DNA damage pathway, evidenced by a reduced expression of DNA polymerase $\beta$ and an increased ATM expression. Our results were consistent with previous reports, in which curcumin caused DNA damage in human pancreatic cancer through the increased phosphorylation of H2A.X and Chk1 and reduced expression of DNA polymerase $\beta$ (36).

We next investigated the mechanism of action for curcumin and IR in the induction of G2/M phase arrest in NHL cells that was mediated through the DNA damage pathway. Cells are blocked in the $\mathrm{G} 2 / \mathrm{M}$ phase during DNA damage (32). The critical target of p53 at G2/M is the Cdk inhibitor $\mathrm{p} 21$, which causes the dissociation of the cdc2 and cyclin complex (37). Consistent with previously published reports $(36,38,39)$, the present study revealed that pre-treatment with curcumin enhanced IR-induced cell arrest in the G2/M phase and concomitantly decreased the percentage of cells in $\mathrm{G} 0 / \mathrm{G} 1$ phases in lymphoma. In the $\mathrm{G} 2 / \mathrm{M}$ phase, cells are more susceptible to the cytotoxic effects of radiotherapy $(40,41)$. At the same time, curcumin enhanced IR-induced expression of p53 and p21. The IR-induced expression of p53 and CDK inhibitor $\mathrm{p} 21^{\text {cipl }}$ as a result of cell treatment with curcumin may thus provide a potential molecular mechanism of action for the induction of cell arrest in $\mathrm{G} 2 / \mathrm{M}$ phase.

DNA damage checkpoints are predominantly associated with the activation of ATM, which plays an important role in DNA repair (32). In previous studies, treatment of non-small cell lung cancer A549 cells and pancreatic cancer cells with curcumin, induced cell cycle arrest through activation of ATM by its phosphorylation (32). Our results further demonstrated the ATM phosphorylation at Ser-1981 as a result of curcumin treatment and IR exposure. To confirm the involvement of ATM phosphorylation in the IR-induced G2/M phase arrest as a result of curcumin treatment, NHL cells were pre-incubated with a specific ATM inhibitor KU55933 followed by IR exposure. Utilization of KU55933 markedly abrogated IR-induced ATM phosphorylation as well as the expression of p53 and p21 $1^{\text {cip1 }}$. These results suggest that the phosphorylation of ATM plays a crucial role in G2/M phase arrest induced by IR and curcumin through the regulation of $\mathrm{p} 53$ and $\mathrm{p} 21^{\mathrm{cip} 1}$ expression.

We previously demonstrated that curcumin sensitizes NHL cells to IR-induced apoptosis through decreasing the $\mathrm{NF}-\kappa \mathrm{B}$ expression and by inhibiting its nuclear localization induced by IR exposure (13). However, the details of the mechanism by which curcumin regulates IR-induced activation of $\mathrm{NF}-\kappa \mathrm{B}$ remains unclear. As previously suggested, the activation of mTOR cascade has been hypothesized to increase the radiation resistance in tumors. Therefore, the mTOR cascade is triggered as a cellular defense mechanism in response to IR exposure to prevent radiation-induced cell death. It has been reported that an mTOR inhibitor was able to sensitize numerous cancer types to DNA damaging agents including IR (42). In addition, mTOR has been reported to be a direct target of curcumin in various tumor cell lines (26). Curcumin inhibited the phosphorylation of mTOR and its downstream targets in numerous cancer cell lines. This further led to the inhibition of cell growth, cell cycle progression and cell proliferation $(43,44)$. Thus, it is reasonable to hypothesize that mTOR may mediate the radiosensitization effect of curcumin in NHL through the regulation of $\mathrm{NF}-\kappa \mathrm{B}$ activation. The treatment of NHL cells with curcumin in this study, significantly inhibited the constitutively expressed mTOR and NF- $\mathrm{B}$ proteins. However, the pre-treatment of NHL cells with curcumin followed by 5 Gy of IR treatment suppressed IR-induced mTOR phosphorylation and p65 nuclear translocation. In addition, rapamycin treatment inhibited the constitutive expression of p65 and suppressed its IR-induced phosphorylation. Taken together, these results strongly suggest that the treatment of NHL with curcumin results in a radiosensitization effect that is mediated through the inhibition of the mTOR-NF- $\kappa$ B pathway. This may be the underlying mechanism of action for curcumin's effect on IR-induced NHL cell death.

In conclusion, our results indicate that curcumin may enhance the NHL cell response to IR through the modulation of the $\mathrm{G} 2 / \mathrm{M}$ phase arrest and the inhibition of the mTOR pathway.

\section{Acknowledgements}

This study was supported by funding from the Department of Health of Liaoning Province provided to Q.Q. (2009A754).

\section{References}

1. Bulut E, Bekcioglu B, Gunhan O and Sener I: Diffuse large B-cell lymphoma with oral manifestations. J Craniofac Surg 22: 1144-1147, 2011.

2. Hainsworth JD: Monoclonal antibody therapy in lymphoid malignancies. Oncologist 5: 376-384, 2000.

3. Li L, Aggarwal BB, Shishodia S, Abbruzzese J and Kurzrock R: Nuclear factor-kappaB and IkappaB kinase are constitutively active in human pancreatic cells, and their down-regulation by curcumin (diferuloylmethane) is associated with the suppression of proliferation and the induction of apoptosis. Cancer 101: 2351-2362, 2004.

4. Aggarwal BB, Banerjee S, Bharadwaj U, Sung B, Shishodia S and Sethi G: Curcumin induces the degradation of cyclin E expression through ubiquitin-dependent pathway and up-regulates cyclindependent kinase inhibitors p21 and p27 in multiple human tumor cell lines. Biochem Pharmacol 73: 1024-1032, 2007.

5. Liu HL, Chen Y, Cui GH and Zhou JF: Curcumin, a potent antitumor reagent, is a novel histone deacetylase inhibitor regulating B-NHL cell line Raji proliferation. Acta Pharmacol Sin 26: 603-609, 2005.

6. Alaikov T, Konstantinov SM, Tzanova T, Dinev K, TopashkaAncheva M and Berger MR: Antineoplastic and anticlastogenic properties of curcumin. Ann NY Acad Sci 1095: 355-370, 2007.

7. Syng-Ai C, Kumari AL and Khar A: Effect of curcumin on normal and tumor cells: role of glutathione and bcl-2. Mol Cancer Ther 3: 1101-1108, 2004.

8. Khafif A, Lev-Ari S, Vexler A, et al: Curcumin: a potential radio-enhancer in head and neck cancer. Laryngoscope 119: 2019-2026, 2009.

9. Chendil D, Ranga RS, Meigooni D, Sathishkumar S and Ahmed MM: Curcumin confers radiosensitizing effect in prostate cancer cell line PC-3. Oncogene 23: 1599-1607, 2004.

10. Sandur SK, Deorukhkar A, Pandey MK, et al: Curcumin modulates the radiosensitivity of colorectal cancer cells by suppressing constitutive and inducible NF-kappaB activity. Int J Radiat Oncol Biol Phys 75: 534-542, 2009. 
11. Yallapu MM, Maher DM, Sundram V, Bell MC, Jaggi M and Chauhan SC: Curcumin induces chemo/radio-sensitization in ovarian cancer cells and curcumin nanoparticles inhibit ovarian cancer cell growth. J Ovarian Res 3: 11, 2010.

12. Javvadi P, Segan AT, Tuttle SW and Koumenis C: The chemopreventive agent curcumin is a potent radiosensitizer of human cervical tumor cells via increased reactive oxygen species production and overactivation of the mitogen-activated protein kinase pathway. Mol Pharmacol 73: 1491-1501, 2008.

13. Qiao Q, Jiang Y and Li G: Curcumin improves the antitumor effect of X-ray irradiation by blocking the NF-kappaB pathway: an in vitro study of lymphoma. Anticancer Drugs 23: 597-605, 2012.

14. Anand P, Sung B, Kunnumakkara AB, Rajasekharan KN and Aggarwal BB: Suppression of pro-inflammatory and proliferative pathways by diferuloylmethane (curcumin) and its analogues dibenzoylmethane, dibenzoylpropane, and dibenzylideneacetone: role of Michael acceptors and Michael donors. Biochem Pharmacol 82: 1901-1909, 2011.

15. Wang Y, Rishi AK, Wu W, et al: Curcumin suppresses growth of mesothelioma cells in vitro and in vivo, in part, by stimulating apoptosis. Mol Cell Biochem 357: 83-94, 2011.

16. Lev-Ari S, Starr A, Vexler A, et al: Inhibition of pancreatic and lung adenocarcinoma cell survival by curcumin is associated with increased apoptosis, down-regulation of COX-2 and EGFR and inhibition of Erk1/2 activity. Anticancer Res 26: 4423-4430, 2006.

17. Liao S, Xia J, Chen Z, et al: Inhibitory effect of curcumin on oral carcinoma CAL-27 cells via suppression of Notch-1 and NF-kappaB signaling pathways. J Cell Biochem 112: 1055-1065, 2011.

18. Binion DG, Otterson MF and Rafiee P: Curcumin inhibits VEGF-mediated angiogenesis in human intestinal microvascular endothelial cells through COX-2 and MAPK inhibition. Gut 57: $1509-1517,2008$

19. Huang $\mathrm{S}$ and Houghton PJ: Targeting mTOR signaling for cancer therapy. Curr Opin Pharmacol 3: 371-377, 2003.

20. Li R, Wang R, Zhai R and Dong Z: Targeted inhibition of mammalian target of rapamycin (mTOR) signaling pathway inhibits proliferation and induces apoptosis of laryngeal carcinoma cells in vitro. Tumori 97: 781-786, 2011.

21. Jazirehi AR, Wenn PB and Damavand M: Therapeutic implications of targeting the PI3Kinase/AKT/mTOR signaling module in melanoma therapy. Am J Cancer Res 2: 178-191, 2012.

22. Chakraborty S, Mohiyuddin SM, Gopinath KS and Kumar A Involvement of TSC genes and differential expression of other members of the mTOR signaling pathway in oral squamous cell carcinoma. BMC Cancer 8: 163, 2008.

23. Darb-Esfahani S, Faggad A, Noske A, et al: Phospho-mTOR and phospho-4EBP1 in endometrial adenocarcinoma: association with stage and grade in vivo and link with response to rapamycin treatment in vitro. J Cancer Res Clin Oncol 135 933-941, 2009.

24. Ekstrand AI, Jonsson M, Lindblom A, Borg A and Nilbert M: Frequent alterations of the $\mathrm{PI} 3 \mathrm{~K} / \mathrm{AKT} / \mathrm{mTOR}$ pathways in hereditary nonpolyposis colorectal cancer. Fam Cancer 9: 125-129, 2010.

25. Kuo SH, Hsu CH, Chen LT, et al: Lack of compensatory pAKT activation and eIF4E phosphorylation of lymphoma cells towards mTOR inhibitor, RAD001. Eur J Cancer 47: 1244-1257, 2011.

26. Beevers CS, Chen L, Liu L, Luo Y, Webster NJ and Huang S: Curcumin disrupts the mammalian target of rapamycin-raptor complex. Cancer Res 69: 1000-1008, 2009.
27. Scapagnini G,ForestiR,Calabrese V, Giuffrida Stella AM, Green CJ and Motterlini R: Caffeic acid phenethyl ester and curcumin: a novel class of heme oxygenase-1 inducers. Mol Pharmacol 61: 554-561, 2002.

28. Kumar R and Atlas I: Interferon alpha induces the expression of retinoblastoma gene product in human Burkitt lymphoma Daudi cells: role in growth regulation. Proc Natl Acad Sci USA 89: 6599-6603, 1992

29. Neijenhuis S, Verwijs-Janssen M, van den Broek LJ, Begg AC and Vens C: Targeted radiosensitization of cells expressing truncated DNA polymerase $\beta$. Cancer Res 70: 8706-8714, 2010.

30. Shrivastav M, Miller CA, De Haro LP, et al: DNA-PKcs and ATM co-regulate DNA double-strand break repair. DNA Repair (Amst) 8: 920-929, 2009.

31. Lukas C, Bartkova J, Latella L, et al: DNA damage-activated kinase Chk2 is independent of proliferation or differentiation yet correlates with tissue biology. Cancer Res 61: 4990-4993, 2001.

32. Huang M, Miao ZH, Zhu H, Cai YJ, Lu W and Ding J: Chk1 and Chk2 are differentially involved in homologous recombination repair and cell cycle arrest in response to DNA double-strand breaks induced by camptothecins. Mol Cancer Ther 7: 1440-1449, 2008.

33. Hickson I, Zhao Y, Richardson CJ, et al: Identification and characterization of a novel and specific inhibitor of the ataxiatelangiectasia mutated kinase ATM. Cancer Res 64: 9152-9159, 2004.

34. Rashid A, Liu C, Sanli T, et al: Resveratrol enhances prostate cancer cell response to ionizing radiation. Modulation of the AMPK, Akt and mTOR pathways. Radiat Oncol 6: 144, 2011.

35. Kunnumakkara AB, Anand $\mathrm{P}$ and Aggarwal BB: Curcumin inhibits proliferation, invasion, angiogenesis and metastasis of different cancers through interaction with multiple cell signaling proteins. Cancer Lett 269: 199-225, 2008.

36. Sahu RP, Batra S and Srivastava SK: Activation of ATM/Chk1 by curcumin causes cell cycle arrest and apoptosis in human pancreatic cancer cells. Br J Cancer 100: 1425-1433, 2009.

37. Taylor WR and Stark GR: Regulation of the G2/M transition by p53. Oncogene 20: 1803-1815, 2001.

38. Calaf GM, Echiburu-Chau C, Wen G, Balajee AS and Roy D: Effect of curcumin on irradiated and estrogen-transformed human breast cell lines. Int J Oncol 40: 436-442, 2012.

39. Lin YC, Chen HW, Kuo YC, Chang YF, Lee YJ and Hwang JJ: Therapeutic efficacy evaluation of curcumin on human oral squamous cell carcinoma xenograft using multimodalities of molecular imaging. Am J Chin Med 38: 343-358, 2010.

40. Moragoda L, Jaszewski R and Majumdar AP: Curcumin induced modulation of cell cycle and apoptosis in gastric and colon cancer cells. Anticancer Res 21: 873-878,2001.

41. Liu E, Wu J, Cao W, et al: Curcumin induces G2/M cell cycle arrest in a p53-dependent manner and upregulates ING4 expression in human glioma. J Neurooncol 85: 263-270, 2007.

42. Schiewer MJ, Den R, Hoang DT, et al: mTOR is a selective effector of the radiation therapy response in androgen receptorpositive prostate cancer. Endocr Relat Cancer 19: 1-12, 2012.

43. Johnson SM, Gulhati P, Arrieta I, et al: Curcumin inhibits proliferation of colorectal carcinoma by modulating Akt/mTOR signaling. Anticancer Res 29: 3185-3190, 2009.

44. Beevers CS, Li F, Liu L and Huang S: Curcumin inhibits the mammalian target of rapamycin-mediated signaling pathways in cancer cells. Int J Cancer 119: 757-764, 2006. 